\title{
Acute Liver Injury with Severe Coagulopathy in Marasmus Caused by a Somatic Delusional Disorder
}

\author{
Lance L. Stein ${ }^{1}$ and Arun B. Jesudian ${ }^{2}$ \\ ${ }^{1}$ Piedmont Transplant Institute, Piedmont Hospital, 1968 Peachtree Road NW, 77 Building, 6th Floor, Atlanta, GA 30309, USA \\ ${ }^{2}$ Division of Gastroenterology, New York Presbyterian Hospital, Weill Medical College of Cornell University, 1305 York Avenue, \\ 4th Floor, New York, NY 10021, USA
}

Correspondence should be addressed to Lance L. Stein, lance.stein@piedmont.org

Received 13 May 2011; Accepted 6 July 2011

Academic Editors: A. Grasso and C. Karaca

Copyright $\odot 2011$ L. L. Stein and A. B. Jesudian. This is an open access article distributed under the Creative Commons Attribution License, which permits unrestricted use, distribution, and reproduction in any medium, provided the original work is properly cited.

\begin{abstract}
Marasmus is a severe form of protein-calorie malnutrition characterized by the depletion of fat stores, muscle wasting, and the lack of edema. In developed countries, marasmus is often the result of anorexia nervosa. Abnormal transaminases with liver synthetic dysfunction have rarely been reported with anorexia nervosa. To our knowledge, we report the first detailed case of acute liver injury with severe coagulopathy (INR > 1.5) in a patient with marasmus due to self-induced calorie restriction caused by a somatic delusional disorder. This case highlights the severity of liver injury that may occur with significant weight loss from self-induced calorie restriction and the rapid normalization of this injury with treatment. It is important for clinicians to be aware of patterns of acute liver injury in patients with severe protein-calorie malnutrition, regardless of the underlying cause.
\end{abstract}

\section{Introduction}

Marasmus is a severe form of protein-calorie malnutrition characterized by the depletion of subcutaneous fat stores, muscle wasting, and the absence of edema. In developed countries, marasmus is commonly the result of anorexia nervosa. Complications of marasmus include bradycardia, hypotension and hypothermia. Abnormal liver transaminases with liver synthetic dysfunction have rarely been reported to occur in anorexia nervosa. To our knowledge, we report the first case of acute liver injury with severe coagulopathy (INR > 1.5) in a patient with marasmus caused by a somatic delusional disorder.

\section{Case Presentation}

A 43-year-old woman was admitted for the evaluation of a $25 \mathrm{~kg}$ weight loss resulting in severe protein malnutrition due to intentional calorie restriction $(300 \mathrm{Kcal} /$ day) for six months. She had no previous medical or surgical history and was not receiving medications. The patient believed that she developed an "autoimmune disease" that improved with self-induced calorie restriction. On presentation, the patient weighed $30.1 \mathrm{~kg}$ (BMI 11), temperature $98.6^{\circ} \mathrm{F}$, heart rate $75 \mathrm{bpm}$, and blood pressure 105/68 $\mathrm{mmHg}$. She was markedly cachectic with temporal wasting, scaphoid abdomen, and normal liver span without stigmata of cirrhosis. She was normally oriented and asterixis was absent. Her admission laboratory testing revealed AST (2895 U/L), ALT $(1868 \mathrm{U} / \mathrm{L})$, alkaline phosphatase $(460 \mathrm{U} / \mathrm{L})$, bilirubin $(2.9 \mathrm{mg} / \mathrm{dL})$, albumin $(3.7 \mathrm{~g} / \mathrm{dL})$, INR (1.9), amylase 188 , lipase 322, CPK 535, normal TSH, negative viral hepatitis and autoimmune serologies, ceruloplasmin $(17 \mathrm{mg} / \mathrm{dL})$, and elevated 24-hour urine copper $(117 \mathrm{mcg})$. Abdominal ultrasound revealed a heterogeneous liver with patent vessels. A slit lamp exam failed to reveal Kayser-Fleischer rings. Psychiatry consultation diagnosed a somatic delusional disorder. She did not fit the DSM-IV TR diagnostic criteria for anorexia nervosa. Five days after the initiation of oral refeeding and intravenous vitamin $\mathrm{K}$, laboratory testing revealed AST (221 U/L), ALT (539 U/L), alkaline phosphatase ( $373 \mathrm{U} / \mathrm{L})$, bilirubin $(1.3 \mathrm{mg} / \mathrm{dL})$, and INR (1.43). During her initial refeeding period, she had occasional episodes of bradycardia, hypothermia, hypotension, and EKG changes with inverted T waves and prolonged QTc. On hospital day 9, her transaminases were improving but still 5-7 times the 


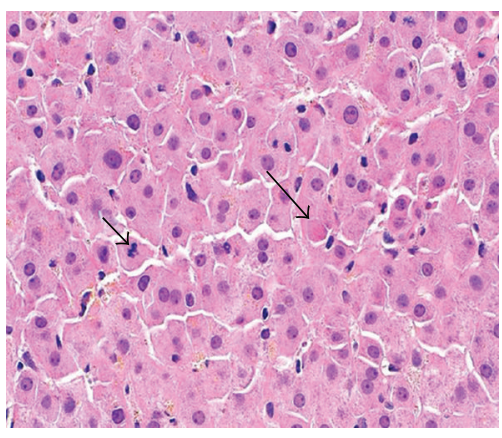

Figure 1: H\&E stain at 400x shows mild acute hepatitis with rare acidophil bodies (long arrow) and increased mitotic figures (short arrow) in the hepatic lobule.

upper limit of normal and a liver biopsy was performed. The liver biopsy revealed mild non-specific acute hepatitis with intrasinusoidal and mild centrilobular perivenular fibrosis, focal necroinflammatory foci, acidophil bodies (long arrow), and increased mitotic figures in the hepatic lobules (short arrow) (Figure 1). Dry copper weight was $53.8 \mathrm{ug} / \mathrm{g}$. ATP7B PCR gene testing was negative for Wilson's disease.

\section{Discussion}

Mild elevations in serum aminotransferase levels have been reported in up to $60 \%$ of patients with anorexia nervosa [1]. However, severe acute liver injury with coagulopathy has rarely been described in the Western literature [2-4]. Coagulopathy that is not improved after vitamin $\mathrm{K}$ repletion appears to coincide with multiorgan dysfunction as seen in our patient [5-7]. The exact pathogenic mechanism of hepatocyte injury is unclear but has been proposed to be caused by hepatic hypoperfusion or more recently due to hepatocyte autophagy $[3,8,9]$.

In summary, this is the first reported case of acute liver injury with severe coagulopathy due to protein-calorie malnutrition caused by a somatic delusional disorder. The clinical presentation and liver histology are similar to reported cases of acute liver injury due to anorexia nervosa. Recognition of the patterns of acute liver injury, which can occur in the absence of hypotension in patients with severe protein-calorie malnutrition is important, regardless of the underlying cause. Treatment consists of hemodynamic support, cautious refeeding, and electrolyte replacement. After appropriate refeeding and weight gain of $4 \mathrm{~kg}$, our patient had normalization of transaminases and coagulation factors by hospital day 30 .

\section{Conflict of Interests}

The authors have no financial conflict of interests to disclose.

\section{References}

[1] S. Umeki, "Biochemical abnormalities of the serum in anorexia nervosa," The Journal of Nervous and Mental Disease, vol. 176, no. 8, pp. 503-506, 1988.

[2] S. Furuta, Y. Ozawa, K. Maejima et al., "Anorexia nervosa with severe liver dysfunction and subsequent critical complications," Internal Medicine, vol. 38, no. 7, pp. 575-579, 1999.

[3] P. E. Rautou, D. Cazals-Hatem, R. Moreau et al., "Acute liver cell damage in patients with anorexia nervosa: a possible role of starvation-induced hepatocyte autophagy," Gastroenterology, vol. 135, no. 3, pp. 840-848.e3, 2008.

[4] J. Rivera-Nieves, K. Kozaiwa, C. R. Parrish, J. Iezzoni, and C. L. Berg, "Marked transaminase elevation in anorexia nervosa," Digestive Diseases and Sciences, vol. 45, no. 10, pp. 1959-1963, 2000.

[5] L. Di Pascoli, A. Lion, D. Milazzo, and L. Caregaro, "Acute liver damage in anorexia nervosa," The International Journal of Eating Disorders, vol. 36, no. 1, pp. 114-117, 2004.

[6] L. Nordgren and C. von Scheele, "Hepatic and pancreatic dysfunction in anorexia nervosa: a report of two cases," Biological Psychiatry, vol. 12, no. 5, pp. 681-686, 1977.

[7] Y. Ozawa, T. Shimizu, and Y. Shishiba, "Elevation of serum aminotransferase as a sign of multiorgan-disorders in severely emaciated anorexia nervosa," Internal Medicine, vol. 37, no. 1, pp. 32-39, 1998.

[8] J. Dowman, R. Arulraj, and I. Chesner, "Recurrent acute hepatic dysfunction in severe anorexia nervosa," The International Journal of Eating Disorders, vol. 43, no. 8, pp. 770-772, 2010.

[9] C. De Caprio, A. Alfano, I. Senatore, L. Zarrella, F. Pasanisi, and F. Contaldo, "Severe acute liver damage in anorexia nervosa: two case reports," Nutrition, vol. 22, no. 5, pp. 572-575, 2006.

\section{Authors' Contribution}

All authors have participated in the clinical care and in the preparation of this paper. 


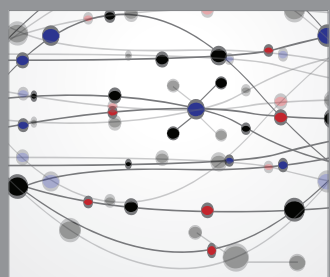

The Scientific World Journal
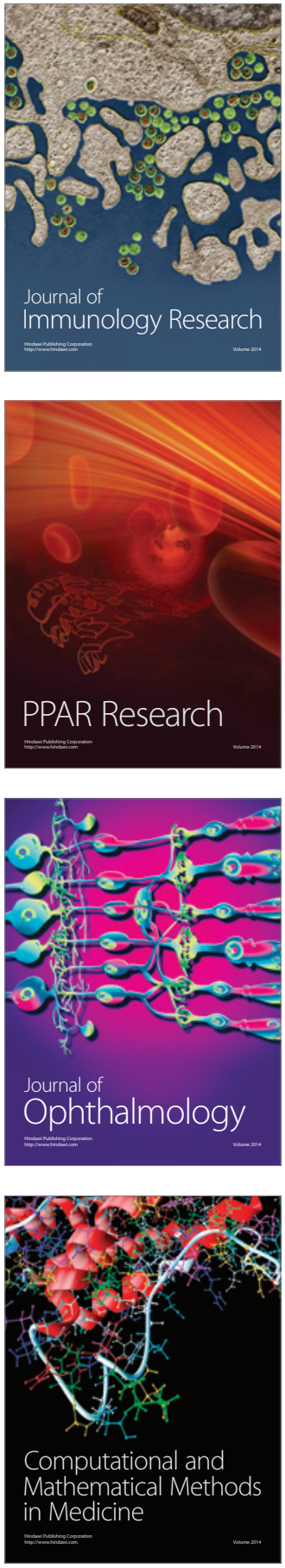

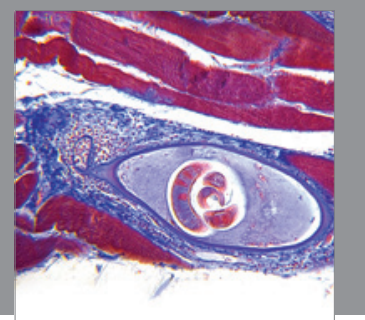

Gastroenterology

Research and Practice
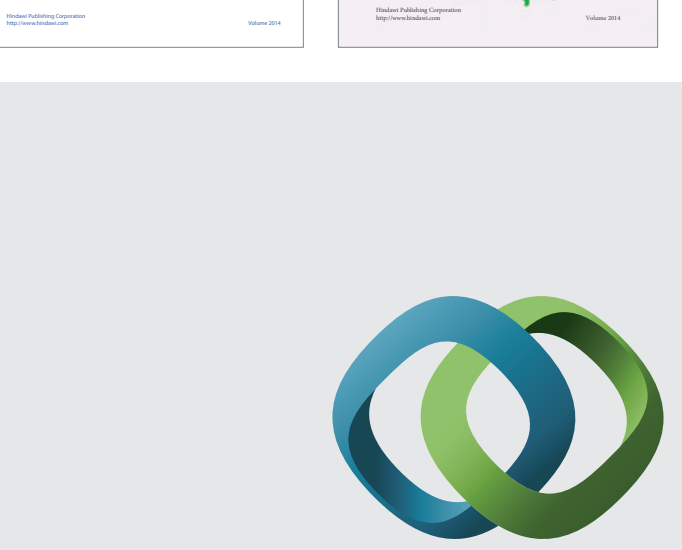

\section{Hindawi}

Submit your manuscripts at

http://www.hindawi.com
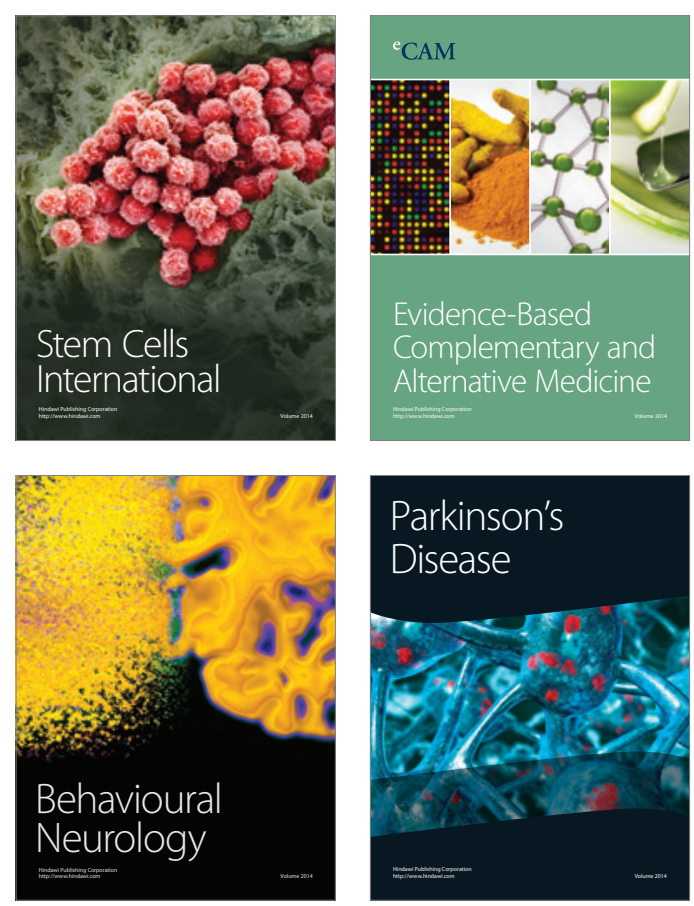

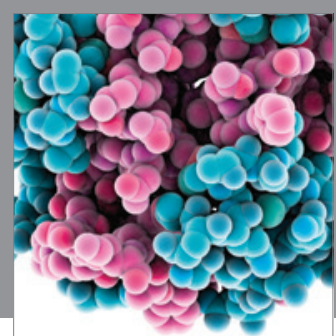

Journal of
Diabetes Research

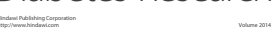

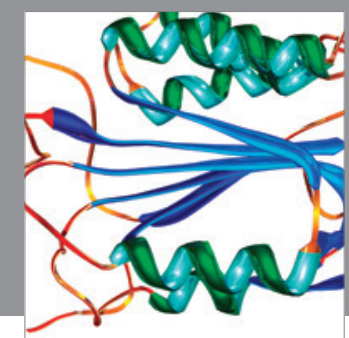

Disease Markers
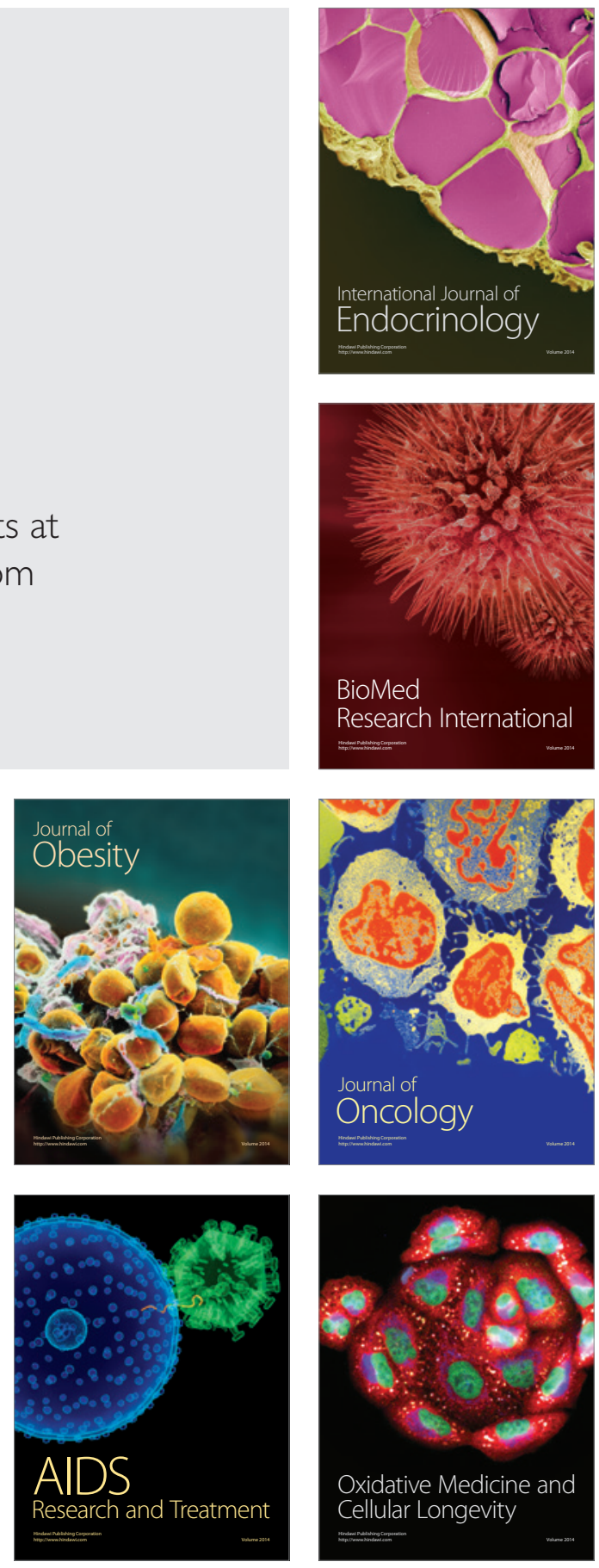